\title{
Electrical and Optical Properties of Indium and Lead Co-Doped $\mathrm{Cd}_{0.9} \mathrm{Zn}_{0.1} \mathrm{Te}$
}

\author{
Yasir Zaman ${ }^{1,2}$, Vineet Tirth ${ }^{3,4}{ }^{\oplus}$, Nasir Rahman ${ }^{5}$, Amjad Ali ${ }^{6, *}$, , Rajwali Khan ${ }^{5, *} \mathbb{C}$, Ali Algahtani ${ }^{3,4}(\mathbb{D}$, \\ Kashif Irshad $\left.{ }^{6} \mathbb{(}\right)$, Saiful Islam ${ }^{7}$ and Tao Wang ${ }^{1}$ (i)
}

1 State Key Laboratory of Solidification Processing, School of Materials Science and Engineering, Northwestern Polytechnical, University, Xi'an 710072, China; yasir.zaman@uos.edu.pk (Y.Z.); taowang@nwpu.edu.cn (T.W.)

2 Department of Physics, University of Sargodha, University Road Sargodha, Punjab 40100, Pakistan

3 Mechanical Engineering Department, College of Engineering, King Khalid University, Abha 61411, Asir, Saudi Arabia; vtirth@kku.edu.sa (V.T.); alialgahtani@kku.edu.sa (A.A.)

4 Research Center for Advanced Materials Science (RCAMS), King Khalid University, P.O. Box No. 9004 Abha 61413, Asir, Saudi Arabia

5 Department of Physics, University of Lakki Marwat, Lakki Marwat 28421, Pakistan; nasir@ulm.edu.pk

6 Interdisciplinary Research Center for Renewable Energy and Power Systems (IRC-REPS), King Fahd

University of Petroleum \& Minerals, Dhahran 31261, Saudi Arabia; Kashif.irshad@kfupm.edu.sa

7 Civil Engineering Department, College of Engineering, King Khalid University,

Abha 61411, Asir, Saudi Arabia; sfakrul@kku.edu.sa

* Correspondence: amjad.ali@kfupm.edu.sa (A.A.); rajwalipak@zju.edu.cn (R.K.); Tel.: +92-333-905-0886 (R.K.)

check for

updates

Citation: Zaman, Y.; Tirth, V.; Rahman, N.; Ali, A.; Khan, R.; Algahtani, A.; Irshad, K.; Islam, S.; Wang, T. Electrical and Optical Properties of Indium and Lead Co-Doped $\mathrm{Cd}_{0.9} \mathrm{Zn}_{0.1}$ Te. Materials 2021, 14, 5825. https://doi.org/ $10.3390 /$ ma14195825

Academic Editors: Michał Borecki and Giorgio Biasiol

Received: 11 August 2021

Accepted: 28 September 2021

Published: 5 October 2021

Publisher's Note: MDPI stays neutral with regard to jurisdictional claims in published maps and institutional affiliations.

Copyright: (c) 2021 by the authors. Licensee MDPI, Basel, Switzerland. This article is an open access article distributed under the terms and conditions of the Creative Commons Attribution (CC BY) license (https:/ / creativecommons.org/licenses/by/ $4.0 /)$.

\begin{abstract}
We have investigated the electrical and optical properties of $\mathrm{Cd}_{0.9} \mathrm{Zn}_{0.1} \mathrm{Te}$ :(In,Pb) wafers obtained from the tip, middle, and tail of the same ingot grown by modified vertical Bridgman method using I-V measurement, Hall measurement, IR Transmittance, IR Microscopy and Photoluminescence (PL) spectroscopy. I-V results show that the resistivity of the tip, middle, and tail wafers are $1.8 \times 10^{10}$, $1.21 \times 10^{9}$, and $1.2 \times 10^{10} \Omega \cdot \mathrm{cm}$, respectively, reflecting native deep level defects dominating in tip and tail wafers for high resistivity compared to the middle part. Hall measurement shows the conductivity type changes from $\mathrm{n}$ at the tip to $\mathrm{p}$ at the tail in the growth direction. IR Transmittance for tail, middle, and tip is about $58.3 \%, 55.5 \%$, and $54.1 \%$, respectively. IR microscopy shows the density of Te/inclusions at tip, middle, and tail are $1 \times 10^{3}, 6 \times 10^{2}$ and $15 \times 10^{3} / \mathrm{cm}^{2}$ respectively. Photoluminescence (PL) spectra reflect that neutral acceptor exciton $\left(\mathrm{A}^{0}, \mathrm{X}\right)$ and neutral donor exciton $\left(\mathrm{D}^{0}, \mathrm{X}\right)$ of tip and tail wafers have high intensity corresponding to their high resistivity compared to the middle wafer, which has resistivity a little lower. These types of materials have a large number of applications in radiation detection.
\end{abstract}

Keywords: I-V measurement; Hall measurement; IR Transmittance; IR Microscopy; PL

\section{Introduction}

Cadmium Zinc Telluride (CZT) is an important and the most promising semiconductor material having many applications in various fields because of its excellent optical and electrical properties suitable for X-rays and $\mathrm{x}$-rays detection, for example, medical imaging, security inspection, high energy physics, and nuclear spectroscopy [1-7]. Generally, the detector operating at room temperature acquires semiconductor materials to have a larger bandgap energy with high resistivity and a low leakage current. However, during the growth of CZT, Te precipitate, cadmium vacancies, and other defects will be formed. The resistivity of the crystal becomes lower, even below $106 \Omega \mathrm{cm}$, which makes it unsuitable for the detector's operation [8]. The Cadmium vacancies $\left(\mathrm{V}_{\mathrm{Cd}}\right)$ also change the conductivity type. Another, the CZT doped with lead (CZT:Pb), shows higher resistivity over $10^{9} \Omega \cdot \mathrm{cm}$ because of the compensation of $\mathrm{V}_{\mathrm{Cd}}$ by dopants [9]. High resistivity CZT are generally grown by the modified vertical Bridgman method [10]. Different dopants have been used to improve CZT crystal quality in order to minimize the defects and to improve 
its resistivity. Indium (In) and In:Al doped CZT have shown a shallow donor below the conduction band, while Al-doped CZT shows shallow acceptors above the valence band [11]. We have doped CZT crystals with In and $\mathrm{Pb}$, which acts as a shallow level and deep level donors respectively, to compensate $\mathrm{Cd}$ vacancies and to improve the performance of crystals. Hall effect measurement systems measures Hall voltage, Hall coefficient, mobility, carrier concentration and type of semiconductors materials, whereas current-voltage (I-V) measurement gives us the most authentic curve, from which we can find the resistivity of the material. Infrared Transmittance also has a relation with CZT crystalline quality [10]. Infrared microscopy is the tool to measure Te inclusions and defects density in the crystal. Photoluminescence (PL) is a non-destructive, sensitive and non-contact tool used to characterize donors and acceptor impurities and other intrinsic defects in CZT crystals [12,13].

In this research paper, the co-doped CZT:In, $\mathrm{Pb}$ has been characterized by using $\mathrm{I}-\mathrm{V}$, Hall measurement, Infrared Transmittance, Infrared microscopy and PL spectra. The wafers have been chosen from different parts of the ingot to know the effect of co-dope on CZT crystal quality.

\section{Materials and Methods}

In the current work, the co-doped $\mathrm{Cd}_{0.9} \mathrm{Zn}_{0.1} \mathrm{Te}$ :(In, $\left.\mathrm{Pb}\right)$ was grown in our laboratory by using a modified vertical Bridgman method (MVB). Growth rate was $1 \mathrm{~mm} / \mathrm{h}$ and temperature gradient was $10 \mathrm{k} / \mathrm{cm}$. The ingot was then cut into wafers with the size of $(7 \times 7 \times 2) \mathrm{mm}^{3}$. The wafers were taken from tip, middle and tail of the ingot and were mechanically polished with magnesium oxide $(\mathrm{MgO})$, then etched with methanol of $2 \%$ $\mathrm{Br}-\mathrm{MeOH}$ for $30 \mathrm{~s}$, rinsed and kept in acetone for some time for analysis. Concentration of indium and lead was $10 \mathrm{ppm}$ and $2 \mathrm{ppm}$ respectively [13].

The electrical properties were analyzed by using an Agilent 4155C setup at room temperature (RT) by making the gold coating on the surfaces of samples. The resistivity was measured by a Van der pauw method based on Hall effect, through which the type of material, charge carrier mobility and charge carrier concentration were obtained at RT. In the experiments, small indium contacts at the four corners of all the samples were used. Te inclusions were characterized by IR transmission microscopy using Micronviewer 7290A, while IR transmittance was tested by a Nicolet Nexus 670 spectrometer in the range of 500 to $4000 \mathrm{~cm}^{-1}$. The optical properties were characterized by PL, in which the samples were attached to a copper finger in a close cryostat with grease and the temperature was cold down to $10 \mathrm{~K}$. An Argon ion laser with a wavelength of $488 \mathrm{~nm}$ was used to excite the spectra. A Triax 550 tri-grating monochromator with a photomultiplier tube (PMT) possessing a spectral resolution of better than $0.3 \mathrm{~nm}$ was connected to the system to collect the spectra emitted from the samples.

\section{Results}

\subsection{Electrical Properties of Co-Doped CdZnTe:(In,Pb)}

Figure 1a shows the holder, wafer size and Ingot grown of CZT:(In,Pb) while Figure $1 \mathrm{~b}$ shows the I-V curves of the three wafers from different parts of the ingot. The results show a linear relationship between I and V, following Ohm's Law. The resistivity of the tip, middle and tail wafers are $1.8 \times 10^{10}, 1.21 \times 10^{9}$, and $1.2 \times 10^{10} \Omega \cdot \mathrm{cm}$ respectively. Native Deep traps were dominated at the tip and tail wafers, showing a higher resistivity than the middle part. 


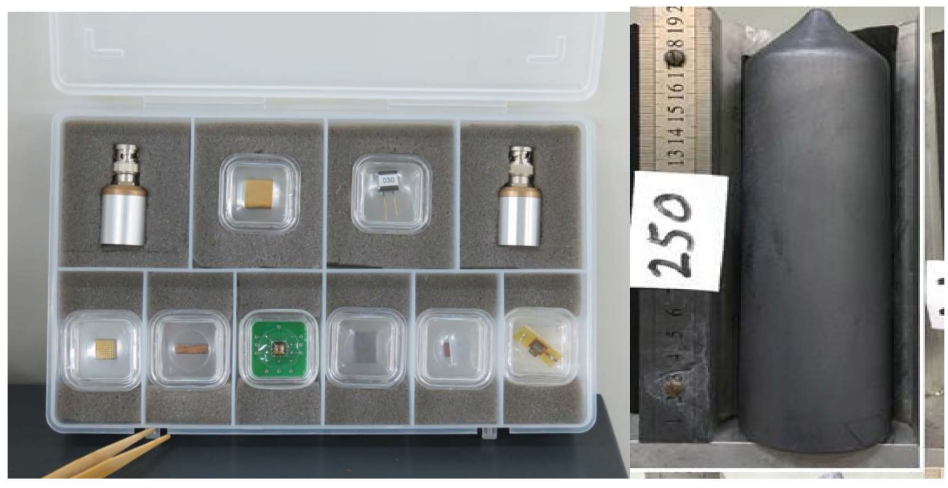

(a)

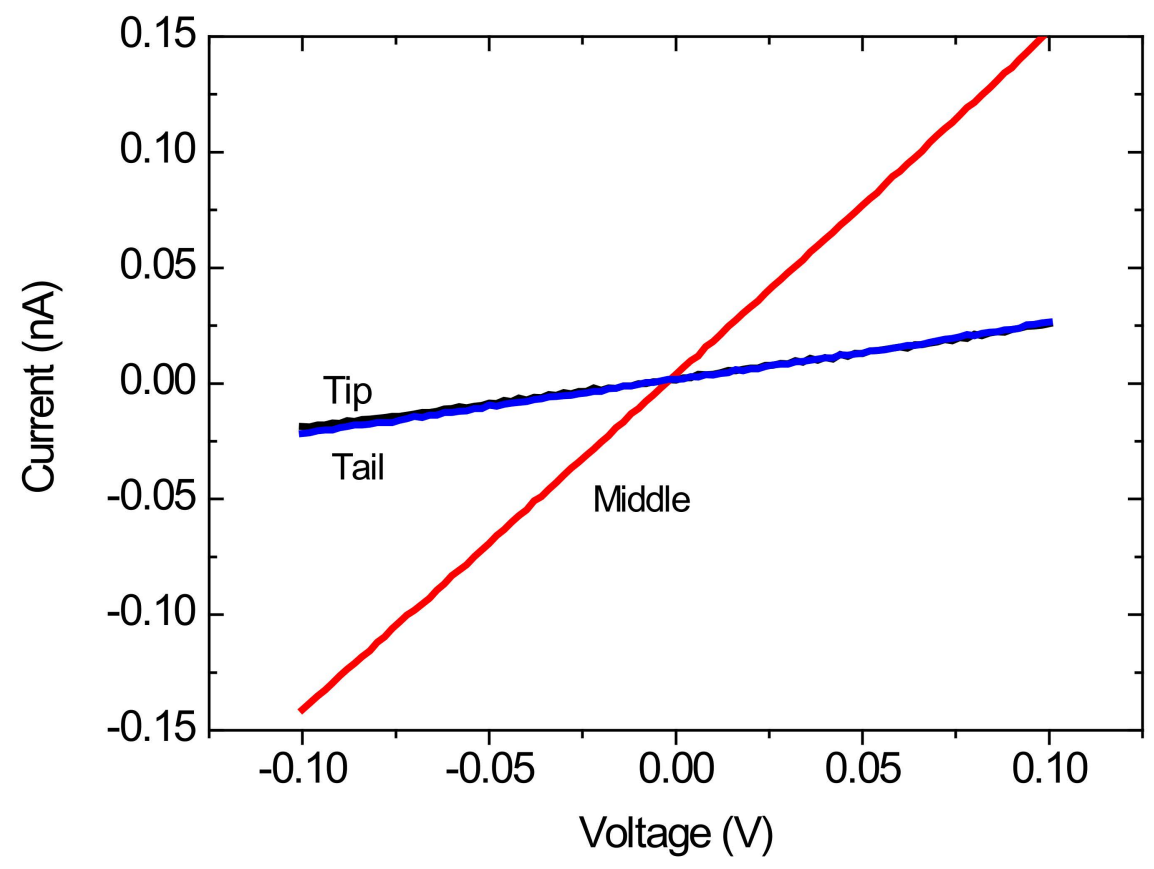

(b)

Figure 1. (a) Configuration of setup i-e holder, wafer size and Ingot CZT:(In,Pb)/Au wafers. (b) The I-V Curves of CZT:(In,Pb)/Au wafers from different parts of the ingot.

Like CdTe [14], CdZnTe is also a semi-insulating material with nonuniform conductivity [15].

Therefore, the high resistivity implies that the densities of twins, Te inclusions and dislocations are relatively high in the initial part of the ingot due to the supercooling effect on the processing of the ignot. The conductivity type of CdZnTe:(In,Pb) is changed from $n$ to $\mathrm{p}$ as we go from tip to tail as shown in Table 1 . The carrier concentration is also pining the Fermi level near the center of the bandgap. Hall mobility, carrier concentration, and resistivity of the wafers are also shown in Table 1.

Table 1. Hall and I-V measurement results of Tip, Middle and Tail wafers of co-doped CdZnTe:(In,Pb) crystals.

\begin{tabular}{ccccc}
\hline Sample Names & Conductivity Type (N or P) & $\begin{array}{c}\text { Hall Mobility } \\
\left(\mathbf{c m}^{2} / \mathbf{V} \cdot \mathbf{S}\right)\end{array}$ & Carrier Conc. $\left.\mathbf{( c m} \mathbf{~}^{-3}\right)$ & Resistivity $\mathbf{(} \cdot \mathbf{c m})$ \\
\hline Tip & $\mathrm{N}$ & $9.24 \times 10^{2} \mathrm{~cm}^{2} / \mathrm{V} \cdot \mathrm{S}$ & $6.45 \times 10^{7} \mathrm{~cm}^{-3}$ & $1.8 \times 10^{10} \Omega \cdot \mathrm{cm}$ \\
Middle & $\mathrm{N}$ & $11.88 \times 10^{2} \mathrm{~cm}^{2} / \mathrm{V} \cdot \mathrm{S}$ & $6.8 \times 10^{9} \mathrm{~cm}^{-3}$ & $1.21 \times 10^{9} \Omega \cdot \mathrm{cm}$ \\
Tail & $\mathrm{P}$ & $13.7 \mathrm{~cm}^{2} / \mathrm{V} \cdot \mathrm{S}$ & $6.78 \times 10^{8} \mathrm{~cm}^{-3}$ & $1.2 \times 10^{10} \Omega \cdot \mathrm{cm}$ \\
\hline
\end{tabular}




\subsection{IR Transmittance}

CZT ingot is transparent at IR wavelengths, but some defects in the crystal may decrease the IR transmission. Therefore, the room temperature IR transmission spectra are usually used to evaluate the quality of the crystal. In this paper, the typical IR transmission spectra with the wavelength in the range of $500-4000 \mathrm{~cm}^{-1}$ for the as-grown crystal are shown in Figure 2.

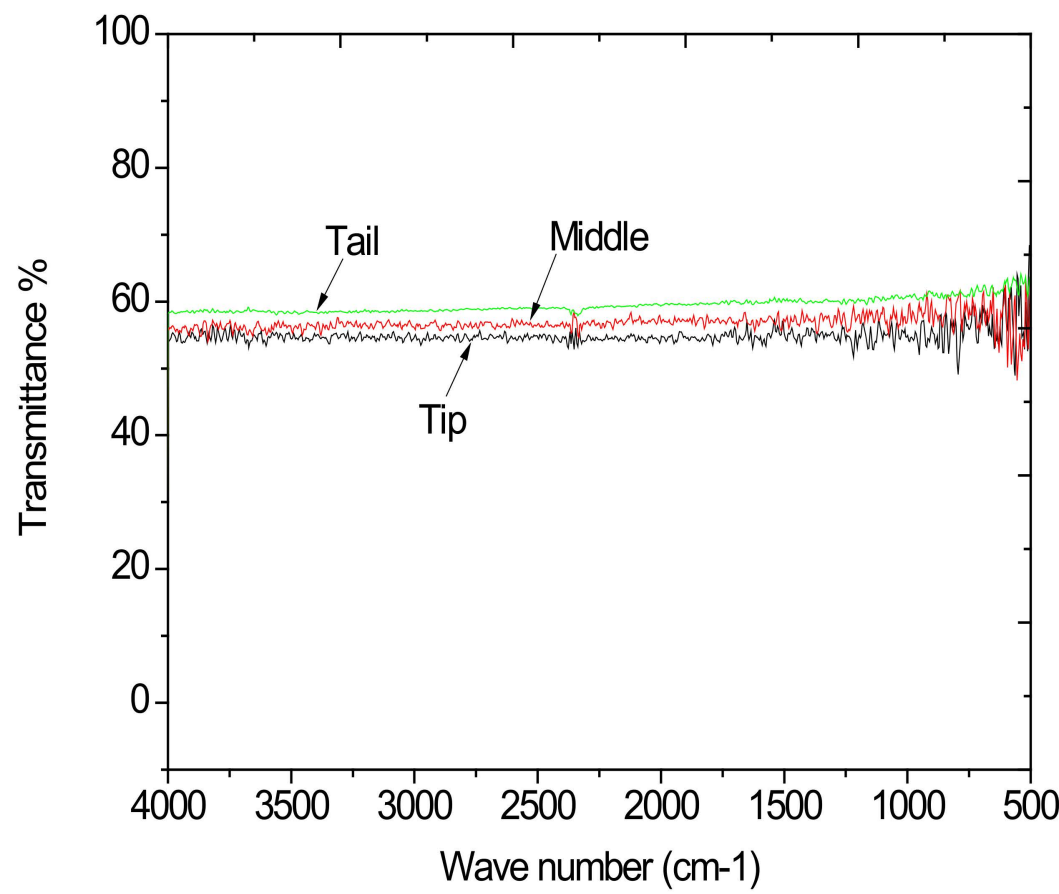

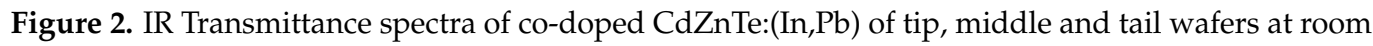
temperature.

The maximum theoretical transmittance for CZT is about 63\% [16] by using Equation (1).

$$
\mathrm{T} \%=\left[(1-R)^{2} / 1-R^{2} \exp ^{-\alpha t}\right]
$$

where $\alpha$ is absorbance coefficient, $t$ is thickness of the wafer, $R=(1-n)^{2} /(1+n)^{2}, n$ is refractive index.

Figure 2 shows that the IR Transmittances of tail, middle and tip wafers are about $58.3 \%, 55.5 \%$ and $54.1 \%$ respectively in the range between $4000-500 \mathrm{~cm}^{-1}$ in descending order. In IR transmittance and variation in Te inclusion concentration is inconsistent; the basic reason for thus is because from tip to tail there is Te segregation, resulting in a different content of Te-rich in front of the growth interface.

It is obvious that the sample with the lowest Te inclusion has the highest IR transmission. Therefore, the Te inclusion is regarded as the main defect affecting the IR transmission besides the lattice absorption. Zaman et al. [13] have calculated the theoretical transmission of this crystal as $65 \%$, and in this paper, sample 2 shows a high IR transmission of $58 \%$, which is near the theoretical limit. Only, the number of Te/Inclusion does not influence transmittance and there is no direct relationship between them. The density of Te/inclusion can decide only the higher transmittance of tail. The size of Te inclusion in the tail may be smaller. The size of Te inclusion is much influenced by the transmittance and not density; therefore, it seems to be consistent.

\subsection{IR Microscopy}

Figure 3 shows that Te inclusions are uniformly distributed throughout the samples, with the size of less than $20 \mu \mathrm{m}$ in diameter [17]. The total densities of the respective wafers 
from tip, middle and tail are $1 \times 10^{3}, 6 \times 10^{2}$ and $15 \times 10^{3} / \mathrm{cm}^{2}$ respectively. It shows that the density of Te inclusions in the tail of the ingot is higher than those from other parts, which could be attributed to the instability of the solid-liquid interface during crystal growth [18]. This indicates that Te inclusions/precipitates are prone to enrichment in the initial region (tip) and the end of the ingot.

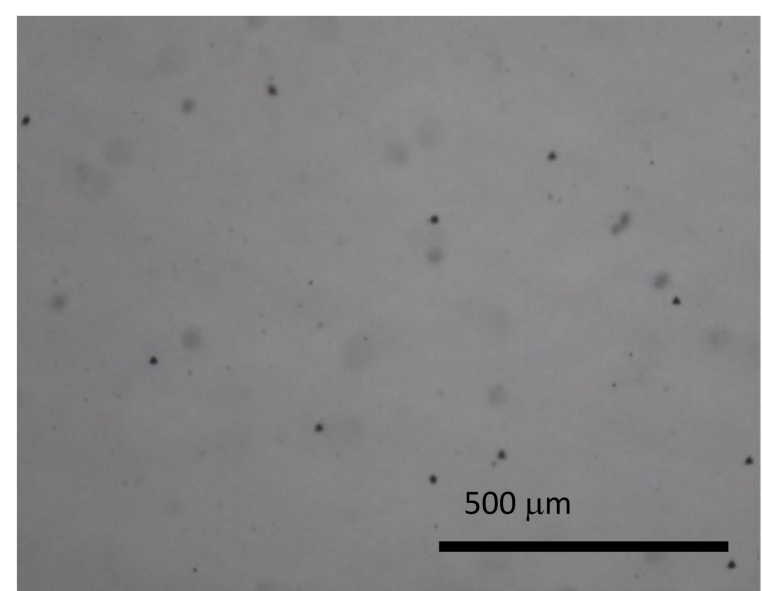

(a)

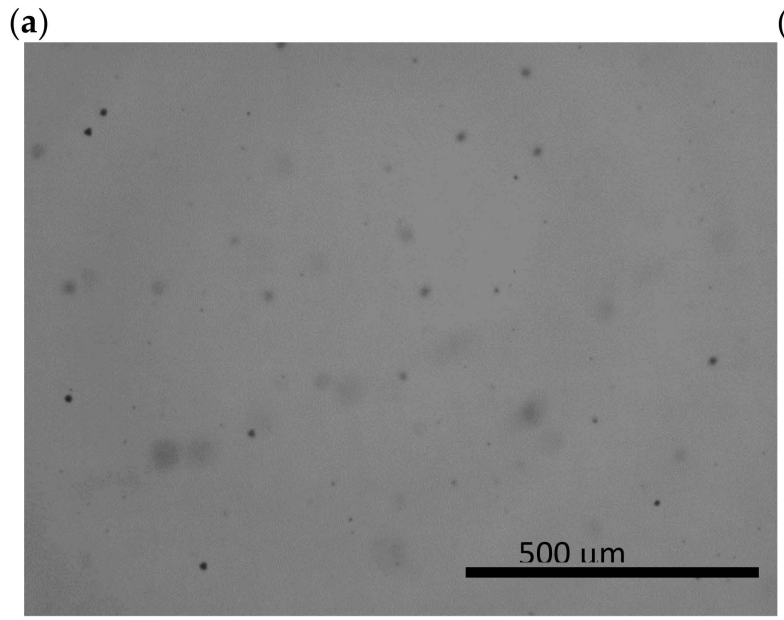

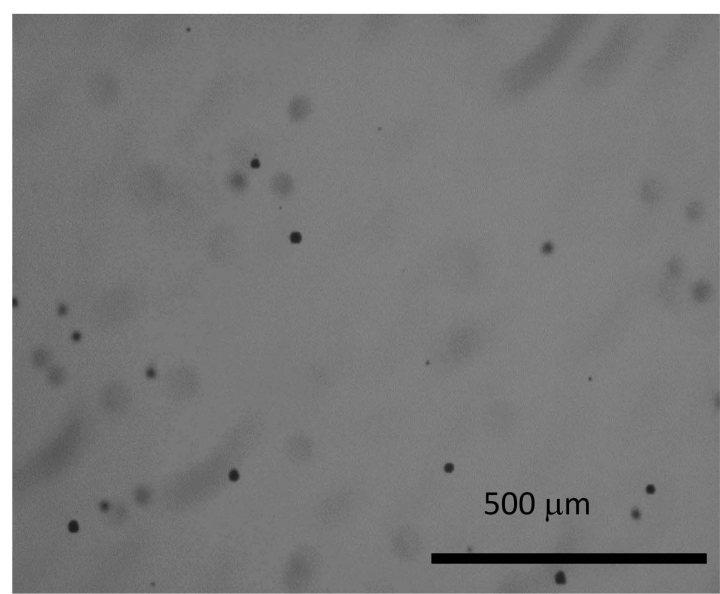

(b)

(c)

Figure 3. Typical IR Microscopy of CZT:In,Pb. (a) tip wafer, (b) middle wafer, (c) tail wafer.

Because the initial part of the ingot is a supercooled area, the Te excess of 10 at.\% was assumed to increase the degree of supercooling. Consequently, the initial region was characterized by an anomalous segregation in relation to the more Te inclusions/precipitates $[17,18]$. With the progressing of the growth, the relative extent of the excess Te was increasing by more and more, resulting in the enriching of Te inclusions at the end of the ingot.

\subsection{PL Measurements of Co-Doped (CZT:In,Pb)}

Figure 4 shows typical PL spectra of tip, middle and tail wafers at $10 \mathrm{~K}$. Several peaks are observed in each wafer. The tip wafer shown in Figure $4 \mathrm{a}$ has many transitions over different energy ranges. A-center peak is observed at $1.501 \mathrm{eV}$, while the donor acceptor pair (DAP) is at the energy of $1.609 \mathrm{eV}$. One Longitudinal optical (1LO) phonon replica at the energy of $1.585 \mathrm{eV}$ is observed, which is very weak. Similarly, neutral acceptor-bound excitons $\left(\mathrm{A}^{0}, \mathrm{X}\right)$ at the energy of $1.644 \mathrm{eV}$ with high intensity and $1 \mathrm{LO}$ replica at $1.622 \mathrm{eV}$ are observed. Neutral donor bound excitons $\left(\mathrm{D}^{0}, \mathrm{X}\right)$ at the energy of $1.656 \mathrm{eV}$ has very low energy compared to $\left(A^{0}, X\right)[19,20]$. For the middle wafer, as shown in Figure $4 b$, A-center with the energy of $1.504 \mathrm{eV}$ and DAP, DAP-1LO, $\left(\mathrm{A}^{0}, \mathrm{X}\right)$ and $\left(\mathrm{D}^{0}, \mathrm{X}\right)$ with the energies of $1.616,1.590,1.649$ and $1.633 \mathrm{eV}$ were observed. The intensity of all the peaks is very low 
except for $\left(\mathrm{A}^{0}, \mathrm{X}\right)$. As shown in Figure 4c, the tail wafer has an A-center at $1.522 \mathrm{eV}$, DAP at $1.629 \mathrm{eV}, \mathrm{DAP}-1 \mathrm{LO}$ at $1.607 \mathrm{eV}, \mathrm{DAP}-2 \mathrm{LO}$ at $1.582 \mathrm{eV},\left(\mathrm{A}^{0}, \mathrm{X}\right)$ at $1.663 \mathrm{eV}$ and $\left(\mathrm{D}^{0}, \mathrm{X}\right)$ at $1.677 \mathrm{eV}$. An intensity ratio of $\left(\mathrm{A}^{0}, \mathrm{X}\right) /\left(\mathrm{D}^{0}, \mathrm{X}\right)$ for tip, middle and tail wafers is $2.163,1.089$ and 0.674 , respectively.

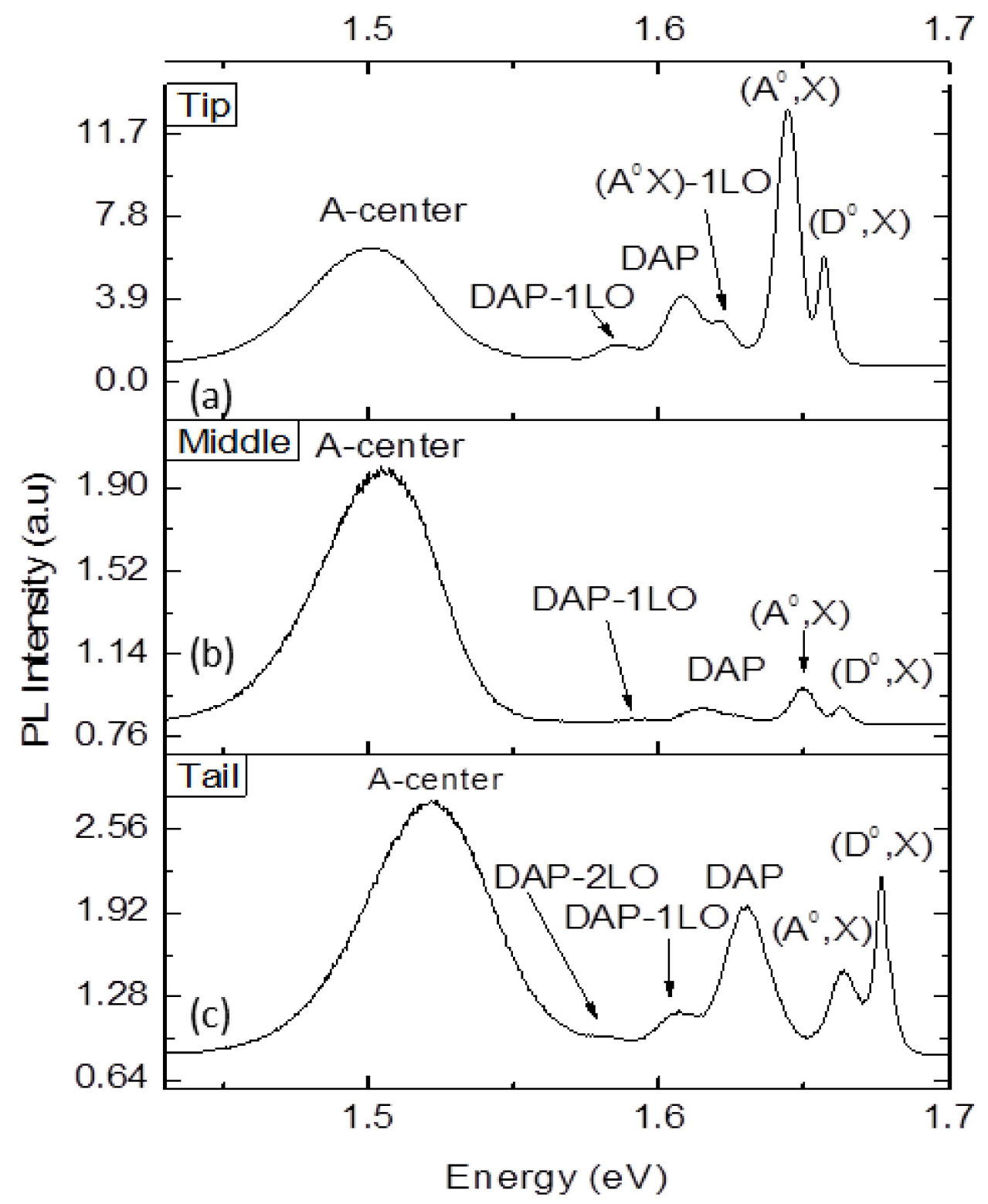

Figure 4. PL spectrum of co-doped CdZnTe: (In,Pb) crystal at $10 \mathrm{~K}$. (a) tip wafer (b) middle wafer (c) tail wafer.

\section{Conclusions}

Our objective was to obtain a material that has a large number of applications in radiation detection. The (CZT:In, $\mathrm{Pb})$ ingot was grown in our laboratory using the modified vertical Bridgman method (MVB). The resistivity values of $1.8 \times 10^{10}, 1.21 \times 10^{9}$ and $1.2 \times 10^{10} \Omega \cdot \mathrm{cm}$ for the tip, middle and tail wafers, respectively, showed complete agreement with Ohm's law measured from I-V curves. The native deep traps introduced in the tip and tail wafers increased their corresponding resistivity values to a higher degree than that of the middle wafer. The maximum value of the Hall mobility of $9.24 \times 10^{2} \mathrm{~cm}^{2} / \mathrm{V} \cdot \mathrm{S}$ (Tip), the carrier concentration of $6.8 \times 10^{9} \mathrm{~cm}^{-3}$ (Middle) and P-type conductivity for (Tail) type sample were measured through Hall measurements, which are considered acceptable 
for the detector's fabrication. Furthermore, the IR Transmittance values vary from 58.3\%, $55.5 \%$, and $54.1 \%$ for the wafers from tail to tip. An IR Microscopy shows the uniform distribution of Te precipitates throughout the samples. PL spectra at $10 \mathrm{~K}$ show that the intensity of $\left(\mathrm{A}^{0}, \mathrm{X}\right)$ and $\left(\mathrm{D}^{0}, \mathrm{X}\right)$ for the wafers from the tip and tail are higher than the middle. The quality of co-doped (CZT:In, $\mathrm{Pb}$ ) crystals was comparable to that of In-doped crystals from the characterization of optical and electrical properties, which are the key technology in various fields, such as medical imaging and security inspection. Moreover, the CZT-based materials are best for radiation detectors and gamma spectrometers, which are highly sensitive room temperature radioactivity monitors

Author Contributions: Y.Z. and R.K. handled the text of this paper and the formatting of this paper. V.T., N.R., A.A. (Amjad Ali), A.A. (Ali Algahtani), K.I., S.I. and T.W. prepared the concept for the paper and did the experimental work for the paper. All authors have read and agreed to the published version of the manuscript.

Funding: This research received the funding from Deanship of Scientific Research, King Khalid University (KKU), Abha-Asir, Kingdom of Saudi Arabia from the grant number R.G.P1./74/42.

Institutional Review Board Statement: Not applicable.

Informed Consent Statement: Not applicable.

Data Availability Statement: The data presented in this study are available on request from the corresponding authors.

Acknowledgments: The authors gratefully acknowledge the Deanship of Scientific Research, King Khalid University (KKU), Abha-Asir, Kingdom of Saudi Arabia for funding this research work under the grant number R.G.P1./74/42.

Conflicts of Interest: The authors declare no conflict of interest.

\section{References}

1. Schlesinger, T.; Toney, J.; Yoon, H.; Lee, E.; Brunett, B.; Franks, L.; James, R. Cadmium zinc telluride and its use as a nuclear radiation detector material. Mater. Sci. Eng. R Rep. 2001, 32, 103-189. [CrossRef]

2. Fiederle, M.; Feltgen, T.; Meinhardt, J.; Rogalla, M.; Benz, K. State of the art of (Cd,Zn)Te as gamma detector. J. Cryst. Growth 1999, 197, 635-640. [CrossRef]

3. Eisen, Y.; Shor, A. CdTe and CdZnTe materials for room-temperature X-ray and gamma ray detectors. J. Cryst. Growth 1998, 184-185, 1302-1312. [CrossRef]

4. Verger, L.; Bonnefoy, J.P.; Glasser, F.; Ouvrier-Buffet, P. New developments in CdTe and CdZnTe detectors for X and $\gamma$-ray applications. J. Electron. Mater. 1997, 26, 738-744. [CrossRef]

5. Limousin, O. New trends in CdTe and CdZnTe detectors for X-and gamma-ray applications. Nucl. Instrum. Methods Phys. Res. 2003, 504, 24-37. [CrossRef]

6. Li, Q.; Jie, W.; Fu, L.; Wang, T.; Yang, G.; Bai, X.; Zha, G. Optical and electrical properties of indium-doped Cd0.9Zn0.1Te crystal. J. Cryst. Growth 2006, 295, 124-128. [CrossRef]

7. Takahashi, T.; Watanabe, S. Recent progress in CdTe and CdZnTe detectors. IEEE Trans. Nucl. Sci. 2001, 48, 950-959. [CrossRef]

8. Nemirovsky, Y.; Asa, G.; Gorelik, J.; Peyser, A. Spectroscopic Evaluation of n-Type CdZnTe Gamma-Ray Spectrometers. J. Electron. Mater. 2000, 6, 691-698. [CrossRef]

9. Suh, J.H.; Cho, S.H.; Won, J.H.; Hong, J.K.; Kim, S.U.; Kim, K.H.; Kim, S.S. Doping effects of lead on CdZnTe crystals. J. Korean Phys. Soc. 2006, 49, 750-754.

10. Li, G.; Jie, W.; Hua, H.; Gu, Z. Cd1-xZnxTe: Growth and characterization of crystals for X-ray and gamma-ray detectors. Prog. Cryst. Growth Charact. Mater. 2003, 46, 85-104. [CrossRef]

11. Wang, C.; Min, J.; Zhou, C.; Liang, X.; Zhao, Y.; Wang, L.; Xia, Y. Analysis of In and Al doped high resistivity CdZnTe crystal. Phys. Status Solidi C 2010, 6, 1498-1500. [CrossRef]

12. Singha, A.; Dhar, P.; Roy, A. A nondestructive tool for nanomaterials: Raman and photoluminescence spectroscopy. Am. J. Phys. 2005, 73, 224-233. [CrossRef]

13. Zaman, Y.; Jie, W.; Wang, T.; He, Y.; Xu, L.; Guo, R.; Xu, Y.; Zha, G. Characterization of CdZnTe co-doped with indium and lead. Nucl. Instrum. Methods Phys. Res. Sect. A Accel. Spectrometers Detect. Assoc. Equip. 2015, 770, 48-51. [CrossRef]

14. Grill, R.; Franc, J.; Höschl, P.; Turkevych, I.; Belas, E.; Moravec, P. Semi-Insulating Te-Saturated CdTe. IEEE Trans. Nucl. Sci. 2005, 52, 1925-1931. [CrossRef]

15. Liu, J.; Mandal, K.C.; Koley, G. Investigation of nanoscale electronic properties of CdZnTe crystals by scanning spreading resistance microscopy. Semicond. Sci. Technol. 2009, 24, 45012. [CrossRef] 
16. Maxey, C.; Gower, J.; Capper, P.; O’Keefe, E.; Skauli, T.; Ard, C. Zn concentration determination in CdZnTe by NIR spectroscopy. J. Cryst. Growth 1999, 197, 427-434. [CrossRef]

17. Ivanov, V.; Alekseeva, L.; Dorogov, P.; Loutchanski, A. Correlation between quality of CZT crystals and spectrometric performance of hemispherical radiation detectors. In Proceedings of the IEEE Symposium on Nuclear Science (NSS/MIC), Rome, Italy, 16-22 October 2004.

18. Xu, Y.D.; Jie, W.Q.; He, Y.H.; Guo, R.R.; Tao, W.A.N.G.; Zha, G.Q. Size and distribution of the inclusions in detector-grade CdZnTe ingots Progress in Natural Science. Mater. Int. 2011, 21, 66-72.

19. Toney, J.; Brunett, B.; Schlesinger, T.; Van Scyoc, J.; James, R.; Schieber, M.; Goorsky, M.; Yoon, H.; Eissler, E.; Johnson, C. Uniformity of Cd1-xZnxTe grown by high-pressure Bridgman. Nucl. Instrum. Methods Phys. Res. Sect. A Accel. Spectrometers Detect. Assoc. Equip. 1996, 380, 132-135. [CrossRef]

20. Chen, H.; Tong, J.; Hu, Z.; Shi, D.T.; Wu, G.H.; Chen, K.T.; George, M.A.; Collins, W.E.; Burger, A.; James, R.B.; et al. Lowtemperature photoluminescence of detector grade $\mathrm{Cd} 1-\mathrm{x} \mathrm{Zn} \times \mathrm{Te}$ crystal treated by different chemical etch-ants. J. Appl. Phys. 1996, 80, 3509-3512. [CrossRef] 